\title{
Construtivismo, pluralismo metodológico e formação de professores para o ensino de ciências naturais
}

\section{Constructivism, methodological pluralism, and teacher formation for natural sciences teaching}

\author{
Marcelo de Carvalho ${ }^{1}$
}

\begin{abstract}
Resumo
Com base em renomados autores da área de educação científica, este trabalho procura mostrar que o ideário construtivista não é uma unanimidade no ensino de Ciências Naturais, nos âmbitos epistemológico e ontológico. Assim sendo, definiu-se como problema a ser investigado a seguinte questão: as críticas feitas pelos autores de educação científica aos pressupostos epistemológicos e ontológicos construtivistas, e às suas conseqüências pedagógicas, seria um indicador de que o conhecimento para o ensino de ciências naturais está propenso a ser oriundo não apenas de estratégias centradas no aluno, mas, sim, de um pluralismo metodológico? No sentido de dar uma resposta ao problema, traçaram-se os seguintes objetivos: 1) levantar, analisar e complementar as objeções feitas por vários autores ao construtivismo em educação científica, no campo da epistemologia, ontologia e pedagogia e, 2) de posse dessas críticas, e como conseqüência delas, propor o "pluralismo metodológico" para o ensino das ciências, tomando por base aspectos do "anarquismo epistemológico" de Paul Feyerabend. O procedimento metodológico do trabalho consistiu em: realizar uma busca dos documentos disponíveis na literatura, principalmente livros e artigos científicos e de posse desses materiais, fazer uma reflexão teórica a fim de alcançar os objetivos propostos. Como resultado fica a recomendação de uma educação científica e, principalmente, dos métodos de ensino a ela associados, não-fixos a sistemas rígidos e limitados, mas que estejam abertos à crítica e a todas as novas descobertas e experiências inovadoras da área.

Palavras-chave: Educação Científica. Construtivismo. Pluralismo Metodológico. Formação de Professores.
\end{abstract}

\begin{abstract}
Based on renowned authors of the Science Education area, this work intends to show that the constructivist background is not a unanimity in Natural Sciences teaching, both in the epistemological and ontological scopes. Thus, the following question was defined as the problem to be investigated: Would the Science Education authors' criticism against the epistemological and ontological presuppositions and their pedagogical consequences, indicate that the knowledge for natural sciences teaching is supposed to be originated not only from strategies centered on the student, but also from a methodological pluralism? In order to answer this question, the following objectives were delineated: 1) to survey, analyze and complement several authors' objections to constructivism in ScienceEducation in the epistemological, ontological and pedagogical fields; 2) in possession of these criticism, and as a consequence of them, to propose Paul Feyerabend's "methodological pluralism". The methodological procedure of this work consisted of an exhaustive search for documents in the available literature, mainly books and scientific papers, and in the possession of these material, to carry out a theoretical reflection with the purpose of reaching the proposed goals. As a result, a science education is recommended along with its associated teaching methods, not connected to rigid and limited systems but ones that are open to criticism as well as to all new discoveries and innovative experiences in this area.
\end{abstract}

Key words: Science Education. Constructivism. Methodological Pluralism. Teachers Formation.

\footnotetext{
${ }^{1}$ Professor Assistente do Departamento de Biologia Geral da Universidade Estadual de Londrina
} 


\section{Introdução}

Tomando por base a máxima construtivista, segundo a qual o aprendiz, por meio de um ativo envolvimento, é o construtor, o arquiteto do seu próprio conhecimento, veremos nas seções subseqüentes que este pressuposto, de estatuto epistemológico, não se distancia do empirismo, e ontologicamente, conduz o conhecimento para o idealismo e também para o relativismo. Isso seria conseqüência de uma parcial leitura construtivista que dá importância a uma exaustiva utilização de estratégias de ensino centradas unicamente no aluno ou à disseminada idéia de negociação.

Deparamo-nos com um número significativo de renomados autores da área de educação científica, cujas idéias demonstraram não haver unanimidade em relação aos preceitos construtivistas. Desse modo, o problema de pesquisa que suscitou essa investigação foi o seguinte: as críticas dos autores de educação científica aos pressupostos epistemológicos e ontológicos construtivistas, e às suas conseqüências pedagógicas, seriam um indicador de que o conhecimento para o ensino de ciências naturais está propenso a ser oriundo não apenas de estratégias centradas no aluno, mas, sim, de um pluralismo metodológico?

No intuito de dar uma resposta à este problema, os objetivos definidos para este trabalho foram:

1) levantar, analisar e complementar as objeções feitas por vários autores ao construtivismo em educação científica, no campo da epistemologia, ontologia e pedagogia e,

2) de posse dessas críticas, e como conseqüência delas, propor o "pluralismo metodológico" para o ensino das ciências, tomando por base aspectos do "anarquismo epistemológico" de Feyerabend (1989).

O trabalho está estruturado em três seções. A primeira explicita as bases epistemológicas e ontológicas do construtivismo radical e as críticas feitas por autores de educação científica a essas bases. A segunda mostra as implicações pedagógicas dessas mesmas bases no ensino de Ciências Naturais. Na terceira, com base na epistemologia feyerabendiana e nas críticas das seções anteriores, estaremos propondo um "pluralismo metodológico" para o ensino de Ciências Naturais. Finalizaremos o trabalho apresentando as conclusões a que chegamos com este estudo.

Levantamento das bases epistemológicas e ontológicas e das implicações filosóficas do construtivismo radical e social no ensino de Ciências Naturais

O foco do nosso levantamento e das conseqüentes reflexões será o construtivismo radical, representado nas idéias de Von Glasersfeld (1989), um de seus principais proponentes (NOLA, 1997; GEELAN, 1997; MATTHEWS, 1994; IRZIK, 2000; NIAZ et.al., 2003). Contudo, as bases e as críticas que se seguem reportar-se-ão, igualmente, sempre que pertinentes, ao construtivismo social.

O construtivismo radical caracteriza-se, fundamentalmente, pelo pressuposto de que o mundo natural preexistente tem um pequeno ou nenhum papel na construção do conhecimento científico, ou seja, o reino natural toma forma exclusivamente por processos individuais (GLASERSFELD, 1989; PHILLIPS, 1997; IRZIK, 2000) ou sociais, para o caso da dissidente vertente social construtivista. Em face disso, o construtivismo radical assume a postura ontológica idealista e epistêmica empirista que destaca que nós não podemos conhecer qualquer realidade além da experiência. Portanto, a verdade torna-se relativa às estruturas conceituais que cada um de nós constrói, tendo cada pessoa acesso apenas às suas próprias experiências.

Tal proposição vem de encontro à ontologia defendida pelos realistas, para os quais a realidade refere-se a um mundo independente, com entidades autônomas das atividades mentais do sujeito ou, em outras palavras, as verdades residem fora do sujeito e o conhecimento deve ser uma representação da realidade. 
Airasian e Walsh (1997) dizem que, em geral, os construtivistas comparam uma "velha" visão do conhecimento com uma "nova" visão construtivista. $\mathrm{Na}$ "velha" visão, tanto o conhecimento quanto as "verdades" residem fora do conhecedor. Neste contexto, o conhecimento seria uma acumulação de verdades, portanto, quanto mais verdades são adquiridas, mais conhecimento se possui. Para a "nova" visão construtivista, esta noção é totalmente rejeitada. Para ela, todo conhecimento é construído e consiste das crenças e experiências dos indivíduos. Portanto, o conhecimento é uma tentativa subjetiva e pessoal.

Tal ponto de vista subjetivista do conhecimento explica a máxima construtivista de que o aprendiz, por meio de um ativo envolvimento, é o construtor, o arquiteto do seu próprio conhecimento, edificador de representações mentais do mundo em torno de si, das quais se utiliza para interpretar novas situações e guiar suas ações (DRIVER, 1989). Conseqüentemente, o construtivismo radical caracteriza-se por ser essencialmente instrumentalista, e representar uma forma de pragmatismo, e relativista. Instrumentalista, por não atribuir nenhum valor de verdade às teorias científicas, e relativista, por vincular a verdade ao contexto social ou psicológico do sujeito. Historicamente, essa base construtivista radical fundamenta-se na idéia de Von Glasersfeld (1989), segundo a qual “Deus é o artífice da natureza, o homem é o deus dos artefatos. Somente Deus pode conhecer o mundo real, porque ele o criou, porém, o conhecimento humano pode somente conhecer o que o conhecimento humano tem construído".

Por sua vez e em oposição à vertente radical, o construtivismo social nega que o conhecimento possa ser gerado individualmente e independente do seu contexto social. Ele defende que o conhecimento comumente aceito é aquele endossado coletivamente.

No entanto, tanto o construtivismo radical quanto o construtivismo social assumem que o conhecimento é dependente da cognição individual ou coletiva de quem o produz e, assim, defendem o subjetivismo do conhecimento, o que leva ambas para o instrumentalismo e, consequentemente, para o relativismo.

Assim, o construtivismo como um todo falha, epistemologicamente, ao defender a idéia de que, para a construção da realidade, bastam as crenças e/ou as experiências dos aprendizes. O perigo de tal atitude está no fato de que, ao priorizar-se o pessoal ou o social, em relação ao mundo natural, deixa-se de distinguir entre objetos teóricos e reais. Para a perspectiva individualista, Matthews (1994) afirma: “[...] o construtivismo é o velho lobo empirista vestido de ovelha contemporânea" ou então [...]" o construtivismo é o velho vinho empirista servido em garrafas novas", pois, ao admitir que o conhecimento possa ser oriundo da contemplação de um objeto e, também, ao não fazer distinção entre objetos teóricos, que são aqueles idealizados pelo sujeito, dos objetos reais, que são regidos exclusivamente pelo mundo físico, este ideário conserva o paradigma aristotélicoempirista, tão criticado pelos próprios construtivistas sociais.

A postura construtivista é preocupante, à medida que se faz necessário observar que não podemos ter a pretensão de inventar o mundo de qualquer maneira. Como lembra Lawson (2000), o mundo físico acaba por limitar nossos saltos especulativos, pois, diante das nossas elucubrações oriundas da observação, sejam elas individual ou coletivamente construídas, o mundo físico é o último árbitro.

Obviamente, não se está a defender um realismo representativo, ou seja, não se postula que as teorias científicas são uma representação fiel da realidade e, portanto, possam ser consideradas como verdadeiras. Defendemos o que Chalmers (1999) chama de "realismo não-representativo" e que, em síntese, defende que o objetivo da ciência não mais seria a busca pela verdade absoluta, mas, sim, que o mundo físico é tal, que nossas teorias atuais são aplicáveis a ele em certo grau, e, em geral, num grau que exceda teorias predecessoras por poder ser aplicada numa variedade mais ampla de circunstâncias. 
As reflexões antecedentes permitem-nos compreender que o construtivismo, ao ignorar a existência de teorias com maior poder explicativo, inegavelmente conduz o conhecimento em direção às bases descritas linhas acima.

\section{Bases construtivistas e suas implicações educacionais}

A partir dos enunciados da última seção, pretendemos concentrar-nos, neste instante, nas críticas que estão sendo feitas às posições construtivistas anteriores. Recordemos que estas críticas deverão, não só passar pelas questões gerais epistemológicas e ontológicas levantadas, mas, igualmente, votar-se-ão para as conseqüentes implicações pedagógicas.

Por influência das teorias piagetianas, o construtivismo radical admite que o conhecimento é construído na interação do sujeito com o objeto do conhecimento (PIAGET, 1977), de modo que, cognitivamente falando, a aprendizagem se dá de uma maneira solitária. Quanto ao papel do professor, este se limita a fomentar e organizar o meio onde o aluno esteja inserido. Portanto, iniciaremos nossa análise pelo subjetivismo proporcionado por esta teoria.

Sob a ontologia subjetivista, foram propostas pela pedagogia construtivista radical estratégias de ensino que privilegiavam o conflito cognitivo. Supunha-se que elas promoveriam a substituição das idéias prévias pelos conceitos científicos. No entanto, segundo Rowell (1983), os resultados obtidos não foram os esperados, pois os alunos evitam das mais variadas maneiras os conflitos. Isso também pode ser facilmente verificado em alguns trabalhos, como, por exemplo, Laburú, Arruda e Nardi (1998); Laburú (1996); Chinn e Brewer (1993); Rowell (1989) e Karmiloff Smith e Inhelder (1974).

Tomando como referencial as críticas a essas estratégias, construtivistas sociais Howe (1996), Driver et al. (1994), Edwards e Mercer (1987), Newman, Griffin e Cole (1989), entre muitos outros, ponderam que o ensino não pode ser visto como um simples mecanismo de reequilibração. $\mathrm{O}$ ensino deve levar em consideração a dimensão sóciointeracionista na análise do processo de ensino, em que o processo de negociação social, os significados e a linguagem do professor vão sendo incorporados pelos alunos, e disso resulta num conhecimento compartilhado.

No entanto, há construtivistas sociais que também não se desvencilharam da mesma problemática dos construtivistas radicais. Apesar da interação social, é da eminente experiência individual desses aprendizes com as outras pessoas que eles criam afirmações e significados próprios. Agora, porém, trata-se de um subjetivismo coletivo ou do endosso coletivo do conhecimento (IRZIK, 2000).

Nessa direção, Osborne (1996, p. 62). critica autores que dão tons pedagógicos sócioconstrutivistas, quando procuram ilustrar a natureza discursiva do conhecimento científico, a partir das representações personalistas e subjetivistas das crianças. Ele afirma, ainda, que a atuação da linguagem e do discurso é limitada, não pela imaginação ou pelas condições culturais, mas pela própria evidência que os cientistas vão juntando. É o mundo que impõe restrições ao pensamento humano e não o contrário, ou como enfatiza esse autor “ podemos pensar no que quisermos, mas não podemos fazer o que quisermos; a natureza sempre limita o nosso discurso"[...].

Como conseqüência, outros problemas podem ser citados. Um deles refere-se à "negociação", extensivamente empregada e que denota a idéia da interação do "expert" (professor ou pares) com o aluno. Chama atenção, nos textos que compartilham teoricamente esta vertente construtivista, a existência, por detrás do termo "negociação", de uma implícita proibição do professor em poder dar direta e claramente a explicação ou em dizer abertamente a resposta correta. Irzik (2000) e Jenkins (2000) compartilham mesma visão, ao comentarem que professores com certa interpretação construtivista 
são relutantes em fornecer a explicação correta para os alunos e deixam a impressão de que desconsideram que cabe a eles desfazer os conceitos equivocados dos alunos.

Negociar, portanto, parece subentender uma imposição pedagógica construtivista na qual o aprendiz deve alcançar o conhecimento de maneira independente, chegando à conclusão sempre e exclusivamente por si próprio.

Neste momento faz-se necessário incluir uma imprescindível variável pedagógica, que é a linguagem, sem dúvida um instrumento pedagógico imprescindível por parte do professor. Para os construtivistas radicais, os elementos da linguagem, como as idéias, os conceitos e a palavra não podem ser transferidos de um usuário para o outro. Esta postura também pode ser encontrada explicitamente em certos destacados construtivistas sociais, quando os vemos afirmar que "O compromisso central da posição construtivista é de que o conhecimento não é transmitido diretamente de um conhecedor a outro, mas é ativamente construído pelo aprendiz [...]" (DRIVER, et al., 1994), ou, "o ensino direto de conceitos é impossível e infrutífero. Um professor que tenta fazer isso geralmente não obtém qualquer resultado, exceto o verbalismo vazio, uma repetição de palavras pela criança, semelhante a de um papagaio, que simula um conhecimento dos conceitos correspondentes, mas que na realidade oculta um vácuo". Em outras palavras o indivíduo atribui um significado subjetivo a uma estrutura conceitual, elaborando através da linguagem um discurso próprio. Mas isso seria contestar as evidências, visto que professores, em conteúdos das mais variadas áreas do conhecimento, com certo grau de complexidade, instruem seus alunos, como fazem os pais com seus filhos nos mais diversos assuntos, inclusive durante as tarefas escolares.

Todo o conhecimento científico, hoje disponível, não é inventado por cada geração, mas, sim, transmitido pela fala e a escrita. Portanto, é ser otimista demais assumir que jovens estudantes possam construir explicações científicas que evoluíram tardiamente na história da humanidade, simplesmente observando fenômenos, gerando e testando hipóteses (JENKINS, 2000).

Tomando o devido cuidado, até mesmo para não cometermos qualquer tipo de injustiça, é necessário salientar que as reflexões precedentes não são generalizáveis a todo o espectro dos sócioconstrutivistas. Por exemplo, em suas análises a respeito do processo discursivo entre professor e alunos, vemos Mortimer (2000) ou Mortimer e Machado (2000) ponderando sobre a importância de se observar a ocorrência da alternância entre dois diferentes tipos de discursos, denominados de persuasão e de autoridade, que estão presentes em sala de aula, em maior ou menor grau. O primeiro tipo tem função dialógica, é aberto, visto que se espera dele a contribuição do aluno e de "várias vozes". O segundo tipo, que explicita o nosso ponto de vista, tem função unívoca, é fechado. Nele é fundamental a transmissão, a consolidação e o reforço de significados de forma inequívoca, onde as enunciações e significados científicos são impostos como fixos, não sendo passíveis de serem modificados, e onde demanda uma incondicional fidelidade (MORTIMER; MACHADO, 2000).

Bailin (2002), ao estudar o desenvolvimento do pensamento crítico em alunos em educação científica, é categórica em afirmar que tal pensamento não é uma prerrogativa de qualquer que seja o ideário pedagógico pois, para que tal pensamento seja alcançado inúmeras variáveis estão envolvidas, como, por exemplo, concepções prévias, contexto no qual os alunos estão inseridos e a própria motivação dos alunos. Indo mais além, a autora diz: "Pesquisas mostram que a capacidade de transferência, por parte dos alunos, da sua criticidade, é limitada. Conceitos de Biologia dificilmente são transferidos autonomamente para outras disciplinas ou demais situações" (p. 367). A importância do professor nesse processo deve ser ressaltada, pois cabe a ele apresentar o conteúdo aos alunos e discutir suas interfaces com as diferentes áreas do saber e suas possíveis implicações cotidianas. 
O ponto que será alvo da nossa análise, a partir de agora, é justamente o modo particularizado de aprender de cada aluno, o que acaba indo de encontro à utilização excessiva, por parte da pedagogia construtivista, de estratégias de ensino centradas nos alunos, como, por exemplo, discussões em grupo.

Trabalhos disponíveis na literatura (expostos na seqüência do trabalho) demonstram que a forma pela qual os alunos aprendem o conteúdo desejado ocorre de várias maneiras e isso, estaria relacionado com a pluralidade cultural e diversificada experiência individual que cada aluno traz para dentro da sala de aula. Portanto, achar que, de uma interação individual ou coletiva com um determinado objeto ou fenômeno, o aluno ou todos eles serão capazes de construir um conhecimento, que é advindo do empírico, permeado de crenças e até mesmo de equívocos grosseiros, é tão ilusório quanto supor que todos os alunos virão a aprender o conteúdo desejado por uma via exclusivamente expositiva. Apenas para ilustrar esse ponto de vista, Laburú, Carvalho e Batista (2001) observou que os indivíduos possuem preferências quanto ao estilo de aprendizagem. Uns estudantes obedecem a um estilo holista, preferindo formar uma visão mais global quando da resolução de problemas. Costumam trabalhar com várias hipóteses, simultaneamente, tendo por hábito adotar uma postura individualista de aprendizagem. Outros são serialistas, pois preferem integrar, passo a passo, tópicos separados daquele que está sendo aprendido e examinar, progressivamente, uma hipótese por vez. Enquanto os primeiros têm preferência em construir uma descrição geral do que é conhecido, os segundos têm uma postura mais operacional, procurando dominar detalhes dos processos e dos procedimentos.

O que dizer, então, quando a esses contextos são, adicionalmente, incorporadas questões étnicas. Shade (1982), Swisher e Deyhle (1987) e Huber e Powewardy (1990) enfatizam que grupos de minorias étnicas e lingüísticas têm sua aprendizagem prejudicada nas situações em que o estilo do grupo dominante é valorizado.
Portanto, a adoção de uma única estratégia de ensino, seja ela qual for, certamente compromete o desempenho de uma parcela de alunos por não respeitar as suas diferenças individuais, quanto a sua maneira de aprender. Por conseguinte, é questionável um esquema educacional baseado numa única perspectiva, que só daria conta das necessidades de um tipo particular de aluno ou alunos e não de outros.

Um outro ponto que também merece atenção se refere ao que Jenkins (2000, p.603) chama de "eliciting students ideas", ou seja, levantar as idéias dos alunos. Na sua opinião, tal estratégia está longe de se tornar clara. Ela seria utilizada para orientar as atitudes do professor ou para auxiliar os alunos a clarificar suas idéias. Ele nos lembra que, quanto a alguns conceitos como força, energia, potência, gravidade ou massa, por fazerem parte das experiências e linguagem diárias dos alunos, não é difícil que estes os tenham, pelo contrário, é esperado que tenham alguma noção ou idéia de alguns deles. No entanto, quanto a outros conceitos como íon, radiação eletromagnética, oxidação, energia livre ou equilíbrio químico, que se encontram longe da experiência diária, torna-se mais difícil que seja adotado o procedimento de levantamento das idéias dos alunos, se não impossível.

Talvez o maior propósito dessa estratégia esteja na possibilidade de fazer com que os alunos tragam para o nível do consciente conceitos que até então eram aplicados de uma maneira meramente intuitiva, e, com isso, procuram escapar de seu poder de comando.

Em suma, as estratégias instrucionais construtivistas, que procuram, encontrar exclusivos caminhos, tendo por base o vagar através de uma exploração intelectual autônoma, ou mesmo coletiva, são questionáveis quanto á sua efetividade. Da mesma forma que o ensino tradicional objetivistaempirista, ao advogar a exclusividade das prescrições de um ensino mecânico, ritualista ou apenas de observação e de audição, centrado exclusivamente no professor, falha em reconhecer o papel ativo do 
aprendiz, falham também, fundamentalmente, as concepções pedagógicas dos construtivistas radicais, ao não admitir que essa abordagem pode levar a uma postura indutivista da aprendizagem

Considerando essas críticas, estaremos, na próxima seção, defendendo uma estratégia pluralista para o construtivismo, no ensino de ciências naturais.

\section{Estratégia Pluralista}

\section{Pluralismo didático}

Paul Feyerabend (1924 - 1994), foi um pensador e filósofo austríaco que, indiscutivelmente, tem seu lugar de destaque na epistemologia contemporânea, por defender uma postura epistêmica contrária a tão difundida práxis científica racionalista. Em contrapartida, ele propõe, na sua mais conhecida obra “Contra o Método" (1989), o “Anarquismo Epistemológico", que se traduz numa renovada e ousada práxis científica denominada de "Pluralismo Metodológico".

Aproveitando-nos desta leitura feyerabendiana, estaremos, a partir de agora, analisando as potencialidades de uma proposta pedagógica pluralista para o ensino de Ciências Naturais.

Assim como Feyerabend (1989), o significado geral de pluralismo que pretendemos empregar é mais o de oposição a um princípio único, absoluto e imutável de ordem, do que uma oposição a tudo e a qualquer organização (REGNER, 1996). Na sua tradução em estratagemas de ensino, a prática pluralista não revela, portanto, ser contra todo e qualquer procedimento metodológico, mas contra a instituição de um conjunto único, frio, restrito, de regras que se pretenda serem universalmente aceitas e principalmente válidas e verdadeiras para toda e qualquer situação de aluno, professor, sala de aula, faixa etária, escola, etnia cultural, lingüística, material, conceito, etc.

Feyerabend (apud REGNER, 1996), faz a seguinte afirmação "todas as metodologias, mesmo as mais óbvias, têm limitações". Obviamente que se trata de uma afirmativa inserida numa discussão epistemológica, mas qualquer modelo pedagógico tem, na sua proposta metodológica, algumas limitações. Uma delas seria, justamente, a que foi discutida na seção anterior, ou seja, as diferenças individuais dos alunos quanto ao seu estilo e motivação de aprender. Outro fator limitador, como nos lembra Gadotti (1993), deve-se ao fato de a evolução das idéias se encontrar ligada à evolução da própria humanidade, ficando, portanto, temporalmente circunstanciada.

Todavia, levando-se em conta que o contexto escolar é permeado por inúmeras variáveis como as que salientamos, isso lhe confere um caráter de grande complexidade. A sala de aula impõe impedimentos às aplicações pedagógicas fundamentadas em exclusivas entidades teóricas e objetivas, redutoras da totalidade da realidade humana. Por essa razão, seria mais prudente vislumbrar as práticas pedagógicas dentro de uma rede de interações, cujos limites seriam dificilmente demarcáveis. Portanto, uma postura pedagógica não deveria ser entendida como definitiva e de caráter geral, principalmente porque, no campo pedagógico, as verdades são discutíveis, não sendo aplicáveis a todo e qualquer indivíduo. Como conseqüência desse argumento pluralista, é interessante que o professor, necessariamente, seja um inconformado ou, como escreve Feyerabend (1989) “o ensino há de basearse na curiosidade e não em exigências, e o professor deveria estimular essa curiosidade, sem recorrer a qualquer método consagrado". Esta falta de conformidade deve ser uma prerrogativa já na formação inicial destes profissionais, para que eles se sintam estimulados a ultrapassar a concepção de uma verdade pedagógica autoritária, como fórmula universal. Assim, um mestre pluralista não se recusa a experimentar uma outra proposta, pois a sua meta e o seu compromisso é com a aprendizagem dos alunos e não com uma fidelidade pedagógica (DAVIS, 2003).

Mas a grande questão é: de que forma a mudança de professores "ordeiros" para "pluralistas" poderse-ia dar? Acreditamos que a resposta esteja na mudança de postura, já que a adoção de uma prática 
pluralista, parte do princípio primordial de que prescrever comportamento único na sala de aula, freqüentemente tem a possibilidade de vir a esbarrar numa perigosa simplificação. No entanto, se centrarmos nossa atenção nos cursos de formação inicial de professores, vemos que, na sua grande maioria, esses cursos incorrem no erro de disseminar entre os futuros professores receitas de ensino ou, em outras palavras, modismos pedagógicos baseados em alguns eufemismos. Fosnot (1998), uma respeitável defensora do ideário construtivista, faz o seguinte alerta: com muita freqüência, no passado, reformas teoricamente bem fundamentadas, ao serem colocadas em prática, tornaram-se o livro de receitas da moda. Portanto, para que o mesmo não aconteça com o construtivismo, os educadores terão que entender criticamente a teoria que está por trás da prática, para que consigam ir além de uma simples postura pedagógica, evitando, assim, uma reforma superficial e baseada em aforismos, perigosamente distorcidos.

Mencionamos algumas estratégias que podem contribuir, de uma forma ou de outra, para a nossa proposta pluralista em sala de aula. Entre elas, podemos citar: favorecer leituras, investigações, questionamentos, gerar conflitos cognitivos, utilizando contradições empíricas e conceituais em nível individual ou, na esfera coletiva, controvérsias entre oposições discrepantes ou antagônicas; incentivar o enfrentamento de problemas, a discussão, os debates de idéias polarizadas e em conjunção com a elaboração de argumentos e justificações de si mesmas; propiciar o levantamento e o teste de hipóteses, a análise e a síntese, fazer uso do recurso de analogias, mapas ou redes conceituais, experimentos mentais, estudo em grupo; estabelecer momentos para que sejam transmitidas informações que precisam ser memorizadas, ordenadas, estruturadas e organizadas através de aulas expositivas, de vídeos, de textos; favorecer atividades manipulativas, de exploração de observação; estar atento ao nível lógico e cognitivo do aprendiz, levando em consideração as suas representações; etc.
Resgatando Pozo (2002), ser-nos-ia factível separar essas estratégias ilustradas em duas categorias básicas de aprendizagem: por associação e por reestruturação. Enquanto a primeira, com característica mecaniscista, é tal que o sujeito adquire uma cópia ou reprodução mais ou menos elaborada da realidade, e está relacionada com estratégias que incrementam a possibilidade de recordar literalmente a informação, sem introduzir alterações na mesma, a segunda, por outro lado, é voltada à idéia de aprender estruturando a realidade a partir dos próprios conhecimentos, e reestruturando estes a partir da realidade. Apesar da conveniência dessa divisão, pensamos que, do ponto de vista da aprendizagem em si não há separação dessas estratégias, pois as duas categorias se tornam solidárias e indistintas.

\section{Comentários finais e conclusões}

Uma das principais contribuições construtivistas para a educação é o fato de que os professores passem a dar o devido valor às concepções dos seus alunos, pois um professor que não leve em consideração tal coisa pode muito bem estar transmitindo uma idéia e os seus alunos entendendo outra. Com efeito, ao estabelecer o seu universo de discurso, o mestre deve estar consciente de que o aluno apropria esse discurso, não como uma cópia, mas a partir das suas representações e da sua “ecologia conceitual” (POSNER et al., 1982).

No que tange especificamente à vertente social construtivista, suas contribuições também devem ser mencionadas.Uma delas é a que dá à linguagem e ao significado um decisivo papel para o desenvolvimento do pensamento, pois este nasce da palavra, que inclui a fala interior (HOWE, 1996). Outra contribuição consiste em que, ao se resgatar o conceito de zona de desenvolvimento proximal de Vygotsky, há um nítido afastamento do construtivismo radical, no que diz respeito ao fundamental papel do professor. A este é atribuída a figura de mediador, por meio do seu falar, do seu mostrar, dos momentos em que ele organiza os conceitos, os pensamentos 
ou as informações soltas que muitas vezes, preenchem lacunas relevantes dos alunos, ou as reestruturam para o entendimento de um determinado assunto. A grande maioria dos aprendizes ficará estacionada em obstáculos intransponíveis, se não puderem contar com um professor que medeie a transmissão da cultura e a análise crítica da mesma, e compartilhe com os alunos os avanços do conhecimento individual. De forma semelhante, atribui-se à palavra "negociar" o sentido de investimento nos mais variados métodos, que vão além da simples aula expositiva, com alunos passivos, e procurem fazer com que o aprendiz se aproprie, significativamente, dos conceitos científicos, através do jogo da argumentação convincente, em direção ao conhecimento científico. Cabe ao professor utilizar os mais variados mecanismos para convencer o aluno de que a explicação científica tem maior abrangência empírica e é superior, neste sentido, do que outras possíveis alternativas. É esta a orientação de "negociar" (e não com a de barganhar significados), para que se possa chegar a um denominador comum arbitrário entre professor-aluno. Dessa forma, entendemos que o construtivismo social demonstra um importante papel no processo de ensino e aprendizagem.

Mas, mesmo sendo o construtivismo social a melhor opção entre os modelos que o precedem, devemos lembrar que o mesmo, a princípio, é limitado, como o são as outras teorias às quais o construtivismo procura se opor. Talvez o perigo maior numa proposta pedagógica, esteja em assumi-la como um único pensamento gerador das melhores estratégias de ensino e aprendizagem para todos os aprendizes, indiscriminadamente. No caso, a força do construtivismo social talvez esteja, justamente, em poder ofertar uma alternativa aos professores que se dedicam exclusivamente ao estilo de transmissão ou à didática convencional. Como diz Oliveira (1993), é importante que o educador saiba que essa idéia de escolha entre teorias é muito arriscada. Isso pode levar a um consumo superficial da teoria tida como a melhor num determinado momento e à desconsideração de outras abordagens que poderiam ser igualmente enriquecedoras. Muitas vezes, em razão de um modismo, uma teoria, quando passa a ser a melhor referência, pode levar também a uma utilização simplificadora de princípios malcompreendidos e, afinal, ao abandono total desnecessário da antiga referência. Assim, a atitude mais fecunda seria o estudo de muitas perspectivas diferentes, para o aprimoramento teórico do profissional e, portanto, para uma elaboração mais refinada da prática educativa, à luz das diversas abordagens estudadas.

Ao final deste trabalho, possivelmente, o leitor poderia achar que, ao defendermos uma proposta pedagógica pluralista, simplesmente descaracterizamos a teoria construtivista. No entanto, não foi isso o que pretendemos. Almejar, porém, um ensino crítico e significativo, em que se insira o aprendiz num processo de conversação, o qual faça com que ele justifique argumentos, estimule e incentive os debates e o trabalho coletivo, a síntese, a análise, respeite e compare as idéias opostas às suas, resolva problemas, construa livremente idéias e argumentos, promova o pensamento crítico, o crescimento intelectual autônomo, é uma pauta que está longe de ser uma prerrogativa exclusivamente construtivista, como concordam muitos outros autores (MATTHEWS, 2000; AIRASIAN; WALSH, 1997; IRZIK, 2000). Na nossa análise, mesmo sendo o construtivismo social a melhor opção entre os modelos que o precedem, devemos lembrar que o mesmo, a princípio, é limitado, como são as outras teorias às quais o construtivismo procura se opor.

\section{Referências}

AIRASIAN, P. W.; WALSH, M. E. Constructivist Cautions. Phi Delta Kappan, Bloomington, v. 78, n. 6, p. 444-449, 1997.

BAILIN, S. Critical Thinking and Science Education. Science \& Education, Dordrecht, v. 11, n. 4, p. 361-375, 2002 
CHALMERS, A. F. O que é Ciência Afinal? São Paulo: Brasiliense, 1999.

CHINN, C. A.; BREWER, W. F. The role of anomalous data in knowledge acquisition: a theoretical framework and implications for science instruction. Review of Educational Research, Washington, v. 63, n. 1, p. 1-49, 1993.

DAVIS, K. S. Change is hard: What Science Teachers are Telling Us About Reform and Teacher Learning of Innovative Practices. Science Education, Hoboken, v. 87, n. 1, p. 3-30, 2003.

DRIVER, R. Students conceptions and the learning of science: Introduction. International Journal of Science Education, London, v. 11, n. 5, p. 481-490, 1989.

DRIVER, R.; HILARY, A.; LEACH, J.; MORTIMER, E.; SCOTT, P. Constructing scientific knowledge in the classroom. Educational Researcher, Washington, v. 23, n. 7, p. 5-12, 1994.

EDWARDS, D.; MERCER, N. Common knowledge: the development of understanding in the classroom. London: Methuen, 1987.

FEYERABEND, P. Contra o método. 3. ed. Rio de Janeiro: Francisco Alves, 1989.

FOSNOT, C. T. (Org). Construtivismo: Teoria, Perspectivas e Prática Pedagógica. Porto Alegre: Art Med, 1998.

GADOTTI, M. História das idéias pedagógicas. São Paulo: Editora Ática,1993. (Série Educação)

GEELAN, D. R. Epistemological anarchy and constructivism. Science \& Education, Dordrecht, v. 6, n. 1-2, p. 15-28, 1997.

HOWE, A. C. Development of science concepts within a Vygotskian framework. Science Education, New York, v. 80, p. 35-51, 1996.

HUBER, T.; POWEWARDY, C. Maximising learning for all students: a review of the literature on learning modalities, cognitive styles and approaches to meeting the needs of diverse learners. Washington: ERIC Clearinghouse on Teacher Education, 1990. (ED 324-289).

IRZIK, G. Back to basis: a philosophical critique of constructivism, Science \& Education, New York, v. 9, p. 621-639, 2000.

JENKINS, E. W. Constructivism in school science education: powerful model or the most dangerous intellectual tendency? Science \& Education, New York, v. 9, p. 599-610, 2000.

KARMILOFF-SMITH, A.; INHELDER, B. If you want to go ahead, get a theory. Cognition, Amsterdam, v. 3, p. 195-212, 1974.
LABURÚ, C. E. La crítica en la enseñanza de las ciencias: constructivismo y contradicción. Enseñanza de las Ciencias, Barcelona, v. 14, p. 93-101, 1996.

LABURÚ, C. E.; ARRUDA, S. M.; NARDI, R. Os programas de Lakatos: uma leitura para o entendimento da construção do conhecimento em sala de aula em situações de contradição e controvérsia. Ciência \& Educação, Bauru, v. 5, n. 2, p. 23-28, 1998.

LABURÚ, C. E.; CARVALHO, M.; BATISTA, I. L. Controvérsias Construtivistas. Caderno Catarinense de Ensino de Física, Florianópolis, v. 18, n.2, 2001.

LAWSON, A. E. How do humans acquire knowledge? And what does that imply about the nature of knowledge? Science \& Education, Dordrecht, v. 9, p. 577-598, 2000.

MATTHEWS, M. R. Vino Viejo em Potellas Nuevas: Un problema com la Epistemologia Constructivista. Enseñanza de Las Ciencias, Barcelona, v. 12, p. 79-88, 1994

MATTHEWS, M. R. Science teaching. The role of history and philosophy of science. New York: Routledge, 1994. (Philosophy of Education Research Library).

MATTHEWS, M. R. Constructivism and science education: an evaluation. In: ENCONTRO DE PESQUISA EM ENSINO DE FÍSICA, 7., 2000, Florianópolis. Atas... Florianópolis, 2000.

MORTIMER, E. F. Linguagem e formação de conceitos no ensino de ciências. Belo Horizonte: UFMG, 2000.

MORTIMER. E. F.; MACHADO, A. H. Anomalies and Conflicts in Classroom Discourse. Science Education, New York, v. 84, n. 4, p. 429-444, 2000.

NIAZ, M.; BENAROCH, A.; MARIN, N.; CARDELINI, L.; ORLIK, Y.; TSAPARLIS, G. Constructivism: Defense or a Continual Critical Appraisal. Science \& Education, Dordrecht, v. 12, n. 8, p. 787-797, 2003.

NEWMAN, D. GRIFFIN, P. COLE, M. The construction zone: working for cognitive change in school. Cambridge: Cambridge University Press, 1989.

NOLA, R. Constructivism in science and science education: a philosophical critique. Science Education, New York, v. 6, n. 1-2, p. 55-83, 1997.

OLIVEIRA, M. K. Vygotsky, aprendizado e desenvolvimento. Um processo sócio-histórico. São Paulo: Scipione, 1993. (Série Pensamento e Ação no Magistério)

OSBORNE J. F. Beyond constructivism. Science Education, New York, v. 80, p. 53-82, 1996.

PHILLIPS, D. C. Coming to grips with radical social constructivisms. Science \& Education, Dordrecht, v. 6, n. 1-2, p. 85-104, 1997. 
PIAGET, J. O desenvolvimento do pensamento: Equilibração das estruturas cognitivas. Lisboa: Dom Quixote, 1977.

POSNER G. J.; STRIKE,K. A.; HEWSON, P. W.; GERTZOG, W. A. Accommodation of scientific conception: Toward a theory of conceptual change. Science Education, New York, v. 66, n. 2, p. 221-227, 1982.

POZO, J. I. Aprendizes e Mestres: a nova cultura da aprendizagem. Porto Alegre: ArtMed, 2002.

REGNER, A. C. K. P. Feyerabend e o pluralismo metodológico. Cadernos Catarinense de Ensino de Física. UFSC, Florianópolis, v. 13, n. 3, p. 231-247, 1996.

ROWELL, J. A. Laboratory counter examples and the growth of understanding in science. European Journal of Science Education, London, v. 5, n. 2, p. 203-215, 1983.

ROWELL, J. A. Equilibration: developing the hard core of the piagetian research program. Human Development, Switzerland, v. 26, n. 2, p. 61-71, 1983a.
ROWELL, J. A. Piagetian epistemology: equilibration and the teaching of science. Synthese. Netherlands, v. 80, p. 141-162, 1989.

SHADE, B. Afro-American cognitive style: A variable in school success. Review of Educational Research, Washington, v. 52, n. 2, p. 219-244, 1982.

SWUISHER, K.; DEYHLE, D. Styles of learning and learning of styles: Educational conflicts for American Indian/Alaskan native youth. Journal of Multilingual and Multicultural Development, St Francis, v. 8, n. 4, p. 345360, 1987.

VONGLASERSFELD, E. Cognition, construction of knowledge and teaching. Synthese, Netherlands, v. 80, p. 121-140, 1989. 